\title{
Influence of starfish grazing on lagoonal microalgal communities: non-competitive mechanisms for unimodal effects on diversity
}

\author{
Jessica Dawson*, Deena Pillay \\ Marine Research Institute, Zoology Department, University of Cape Town, Rondebosch, 7701 Cape Town, South Africa
}

\begin{abstract}
We quantified the effects of grazing by the starfish Parvulastra (=Patiriella) exigua on microalgal assemblages in a lagoon on the South African west coast. This starfish is common on rocky shores in South Africa and Australia, but rarely occurs on soft sediments. Although grazing is well known to be a dominant structuring agent of marine systems, the influence of grazing starfish is poorly documented. Our results indicate that at natural densities, $P$. exigua plays an important role in structuring soft-sediment microalgal assemblages, having no significant effect on microalgal biomass, but reducing microalgal abundance probably through consumption. Interestingly, concentrations of extracellular polymeric substances (EPS) increased with densities of $P$. exigua, indicating a potentially important ecological role of this starfish in enhancing carbohydrate levels on the sediment either through mucus addition or stimulation of bacterial biomass. Taxonomic richness and diversity of microalgae showed classical hump-shaped responses to increasing starfish density. Our findings are discussed in the context of the intermediate disturbance hypothesis, which proposes that disturbance promotes diversity at intermediate intensities by eliminating dominant species and allowing poor competitors to co-exist. We also present evidence for a mechanism based on non-competitive interactions to explain the promotive effects of this starfish on microalgal diversity, arising from the ability of this species to enhance sedimentary EPS levels. Our results collectively indicate that $P$. exigua plays an important role in regulating diversity and richness of microalgal assemblages and concur with previous assertions that this starfish plays an underestimated role in structuring intertidal systems.
\end{abstract}

KEY WORDS: Extracellular polymeric substances - EPS · Diversity · Microalgae · Competition · Plant-animal interaction

\section{INTRODUCTION}

Grazing organisms play crucial roles in the structuring of assemblages in marine (Lubchenco \& Gaines 1981, Anderson \& Underwood 1997, Jackson et al. 2009, Pillay et al. 2010a) and freshwater (Hargrave 1970, Flint \& Goldman 1975, Morrisey 1988) ecosystems around the world. Through consumptive (feeding) and incidental (disturbance) removal, grazers can alter fundamental ecological processes and properties such as rates of succession and recruitment (Levinton \& Stewart 1982), competitive interactions (Branch \&
Branch 1980), resource availability and habitat heterogeneity (Jackson et al. 2009). Grazers can also have both positive and negative effects on communities depending on grazer density and species (Hargrave 1970, Flint \& Goldman 1975, Morrisey 1988, Pillay et al. 2009) through both direct and indirect mechanisms (Anderson 1999).

Grazers are prominent as structuring agents of communities in soft-sediment and hard substrata in aquatic ecosystems. Grazers can often enhance richness and diversity of communities, with competitive mechanisms being often cited (e.g. Lubchenco 1978, 
Lubchenco \& Gaines 1981). Through consumption, grazers remove competitively dominant species that monopolise habitats, thereby allowing sub-dominants to establish. However, the role of non-competitive mechanisms by which grazers promote diversity are poorly understood and reported in the literature, even though such pathways are potentially significant (Pillay et al. 2010a).

From a benthic perspective, non-competitive interactions are likely to be of importance in promoting diversity in aquatic soft-sediment ecosystems, as competition and competitive exclusion have rarely been shown to be important structuring forces in these habitats (Peterson 1979, Wilson 1990). Soft sediments are 3dimensional ecosystems, allowing organisms to partition space vertically, by burrowing, thereby potentially minimising competition for space and food (Wilson 1990, Seitz 1998, Little 2000). This is in stark contrast to the situation on hard substrata, which are 2-dimensional systems, in which competition for resources is comparatively more intense because organisms cannot burrow (Little \& Kitching 1996). Also of importance in soft-sediment ecosystems is the potential for organism-substrate interactions to structure assemblages (Aller et al. 2001). Disturbance or stabilisation of sediments or modification of biogeochemical properties and processes in sediments are potentially important non-competitive mechanisms by which grazers may structure communities and influence diversity.

In this paper, we experimentally evaluate the influence of the grazing starfish Parvulastra (=Patiriella) exigua on intertidal soft-sediment microalgal assemblages in Langebaan Lagoon, a marine-dominated system on the west coast of South Africa. We then present a hypothesis on a non-competitive pathway by which this starfish may promote microalgal diversity in marine sedimentary habitats, arising from its ability to enhance levels of sediment extracellular polymeric substances (EPS). EPS are usually exuded by microorganisms such as microalgae and bacteria that live on the surfaces of sediments, but can also be generated as mucus by larger invertebrates such as gastropods and polychaetes (Wotton 2004a). EPS produced by bacteria and microalgae usually coat the sediment surface and create biofilms. EPS offer microbes several advantages, including protection from desiccation, grazing and resuspension. EPS also facilitate trapping and retention of nutrients and organic material from the water column (van Loosdrecht et al. 1990, Wotton 2004b). Substrate-associated EPS in turn play important ecological roles; they are food for invertebrates (Decho 1990), stabilise sediments, promote laminar flow of over-lying water (Paterson \& Hagerthey 2001) and are important in the settlement and recruitment of benthic species (Lam et al. 2005, Pillay et al. 2007). All of these effects have important implications for the structuring of soft-sediment assemblages.

The starfish in question (Parvulastra exigua) is a small grazing species (roughly $5 \mathrm{~cm}$ across arms) that is common in Australian and South African intertidal rocky-shore habitats (Branch \& Branch 1980, Jackson et al. 2009), but rarely occurs in soft-bottomed systems such as estuaries and lagoons (Pillay et al. 2010a). Starfish play important roles in structuring marine benthic communities, but most studies have been based on their roles as predators (Paine 1974, McClintock \& Lawrence 1985, Stevenson 1992). The influence of grazing by starfish is poorly documented in rocky substrata and even less so in soft-sediment systems (Arrontes \& Underwood 1991, Jackson et al. 2009, Pillay et al. 2010a). Previous work has indicated that $P$. exigua plays a significant role in structuring microalgal biofilms in rocky shores (Jackson et al. 2009) and macrofaunal assemblages in soft sediments (Pillay et al. 2010a). Both studies also indicate that this species has been underrated in terms of its ability to structure benthic marine communities. The present study is also motivated by the fact that $P$. exigua occurs almost exclusively in and around seagrass (Zostera capensis) beds in Langebaan Lagoon and that the abundance of both species has been declining in the system (Pillay et al. 2010b). This experiment is therefore important in understanding the consequences of further losses of this starfish for intertidal sandflats in Langebaan Lagoon.

\section{MATERIALS AND METHODS}

Study site. The experiment was undertaken at Bottelary (330 $08^{\prime} 45^{\prime \prime} \mathrm{S}, 18^{\circ} 05^{\prime} 29^{\prime \prime} \mathrm{E}$ ) in Langebaan Lagoon, on the west coast of South Africa. The lagoon is approximately $14 \mathrm{~km}$ long and 1.5 to $3 \mathrm{~km}$ wide and receives minimal freshwater inflow. Wave action is low and the lagoon is sheltered from the effects of oceanic swell, although disturbance can occur in the face of southeasterly winds (Day 1959).

Experimental design. Field experiments that used randomly interspersed inclusion/exclusion cages were undertaken from August to October 2009 in high shore zones adjacent to beds of the eelgrass Zostera capensis. Cages covered an area of approximately $200 \mathrm{~m}^{2}$ and were 4 to $5 \mathrm{~m}$ apart. Five treatments were used, viz. cages excluding Parvulastra exigua and cages including $P$. exigua at densities of 1 (10 ind. $\left.\mathrm{m}^{-2}\right), 2$ (20 ind. $\mathrm{m}^{-2}$ ), 3 (30 ind. $\mathrm{m}^{-2}$ ) and 4 (40 ind. $\mathrm{m}^{-2}$ ) starfish per cage, with each treatment being replicated 5 times. The densities of starfish used were within the range of those found on sandflats in Langebaan Lagoon (Pillay et al. 2010a). Procedural controls, such as partial cages, 
were not employed as these would have allowed starfish to escape and confounded interpretation of cage effects (Virnstein 1978, Jackson et al. 2009, Pillay et al. 2010a). In this experimental design, any cage effect would have been held constant across all treatments and all patterns observed would have been attributable to the effects of $P$. exigua. The cages were rectangular (length $=40 \mathrm{~cm}$, breadth $=25 \mathrm{~cm}$, area $=$ $0.1 \mathrm{~m}^{2}$ ) and made of $5 \mathrm{~mm}$ mesh-size plastic netting that covered the sides and $10 \mathrm{~mm}$ mesh-size plastic meshing that covered the top. Each cage penetrated $10 \mathrm{~cm}$ into the sediment and protruded $10 \mathrm{~cm}$ above the sediment. Sediment cores, from the top $1 \mathrm{~cm}$ of sediment, were collected from each cage to determine microalgal community structure, chlorophyll a (chl a) concentrations and levels of EPS 1 mo after the cages were installed. The experiment was intended to run for a 2 mo period with sample collection taking place after 1 and 2 mo. The data presented in this paper are for the 1 mo period. A severe storm resulted in the loss of several cages following the 1 mo period, which prevented further temporal replication of the experiment. Cores were collected and analysed as stated below.

Sample collection and analyses. For EPS levels, cores $(\mathrm{n}=3$, diameter $=2 \mathrm{~cm}$, depth $=1 \mathrm{~cm})$ were collected from each cage and stored overnight at $-20^{\circ} \mathrm{C}$ for $24 \mathrm{~h}$ prior to analysis. EPS concentrations were determined using the phenol-sulfuric acid assay (Dubois et al. 1956; Underwood \& Paterson 1995), in which $2 \mathrm{ml}$ of distilled water was added to a $2 \mathrm{~g}$ homogenised sub-sample of each sediment core, followed by $1 \mathrm{ml}$ of $5 \%$ aqueous phenol (w/v) and $5 \mathrm{ml}$ of concentrated sulphuric acid $\left(\mathrm{H}_{2} \mathrm{SO}_{4}\right)$. The mixture was diluted 10-fold and absorbance was measured spectrophotometrically (Merck Spectroquant Pharo 100) against a reagent blank. Calibration was performed using a standard curve of absorbance against glucose concentration at $485 \mathrm{~nm}$.

For microphytobenthic biomass, cores ( $\mathrm{n}=3$, diameter $=2 \mathrm{~cm}$, depth $=1 \mathrm{~cm}$ ) were collected from each cage and refrigerated in $30 \mathrm{ml}$ of $90 \%$ acetone for $48 \mathrm{~h}$ to extract chl a. Fluorescence was measured using a Turner Designs Trilogy fluorometer.

Additional sediment cores for microalgal community structure $(\mathrm{n}=3$, diameter $=2 \mathrm{~cm}$, depth $=1 \mathrm{~cm})$ were collected from each cage and preserved in Lugol's solution (1\% final solution; Taylor et al. 2007). Each sample was homogenised for $10 \mathrm{~s}$ using a vortex mixer and left to settle for $30 \mathrm{~s}$, after which a $5 \mathrm{ml}$ liquid subsample was removed and centrifuged for $10 \mathrm{~min}$ at $805 \times g$. The supernatant was pipetted off and $0.3 \mathrm{ml}$ of distilled water was added to the pellet and then resuspended using a vortex mixer. A $30 \mu$ liquid sub-sample was withdrawn and placed on a slide and viewed using a Leica DM 750 compound microscope fitted with a
Leica ICC50 camera at 40× magnification. Microalgae were counted from 10 fields of view per core. The data from the 10 fields of view for each of the 3 cores from each cage were pooled, thus generating a sample size of 5 per treatment. Because of the difficulty in identifying microalgae to species level, microalgae were identified as morphospecies.

Statistical analyses. All multivariate analyses were performed using PRIMER v. 6 based on unstandardised and untransformed abundance data. Non-metric multidimensional scaling (NMDS) was used to visually assess microalgal community structure among treatments, based on resemblance matrices generated from Bray-Curtis similarities. Analysis of similarity (ANOSIM) tested for statistical differences among treatments, with pairwise tests highlighting statistically significant inter-treatment differences. The DIVERSE function was used to calculate the following community parameters for each treatment: total abundance of microalgae $(\mathrm{N})$, taxonomic richness $(S)$ and Shannon-Wiener diversity (to the base e, $H^{\prime}$ ).

Statistica v. 8 was used to apply 1-way ANOVA to test for effects of starfish density on EPS levels, chl a concentrations and microalgal community parameters $\left(\mathrm{N}, S, H^{\prime}\right)$ together with post hoc Tukey's test for intertreatment comparisons. SPSS v. 17 was used to apply a curve estimation function to identify the model that best explained the relationship between EPS levels, chl a concentrations, microalgal community parameters $\left(\mathrm{N}, S, H^{\prime}\right)$, abundance of microalgal taxa and starfish density. The assumptions of normality and homogeneity of variance required for parametric testing were assessed using Kolmogorov-Smirnov and Levene's tests, respectively. When these assumptions were not met, data were log-transformed and parametric tests were applied.

\section{RESULTS}

Total sediment EPS concentrations (Fig. 1) were significantly influenced by Parvulastra exigua densities (ANOVA: $F_{4,20}=4.197, \mathrm{p}=0.013$ ) in a unimodal manner $\left(\mathrm{R}^{2}=0.419, \mathrm{p}<0.001\right)$. EPS concentrations were significantly greater in high starfish densities (30 and 40 ind. $\mathrm{m}^{-2}$ ) than in the controls $\left(0\right.$ ind. $\mathrm{m}^{-2}, \mathrm{p}<0.05$ for all). In contrast, microalgal biomass ( $\mathrm{chl} \mathrm{a}$ ) was not significantly influenced by $P$. exigua densities $\left(F_{4,20}=\right.$ 0.078, p = 0.988; Fig. 1).

NMDS ordination (Fig. 2) visually indicated that microalgal community structure in sediments was different between the 5 starfish densities used; this was statistically confirmed by ANOSIM ( $p=0.001)$. In addition, pairwise testing ( $p=0.008$ in all cases) indicated that microalgal community structure differed signifi- 

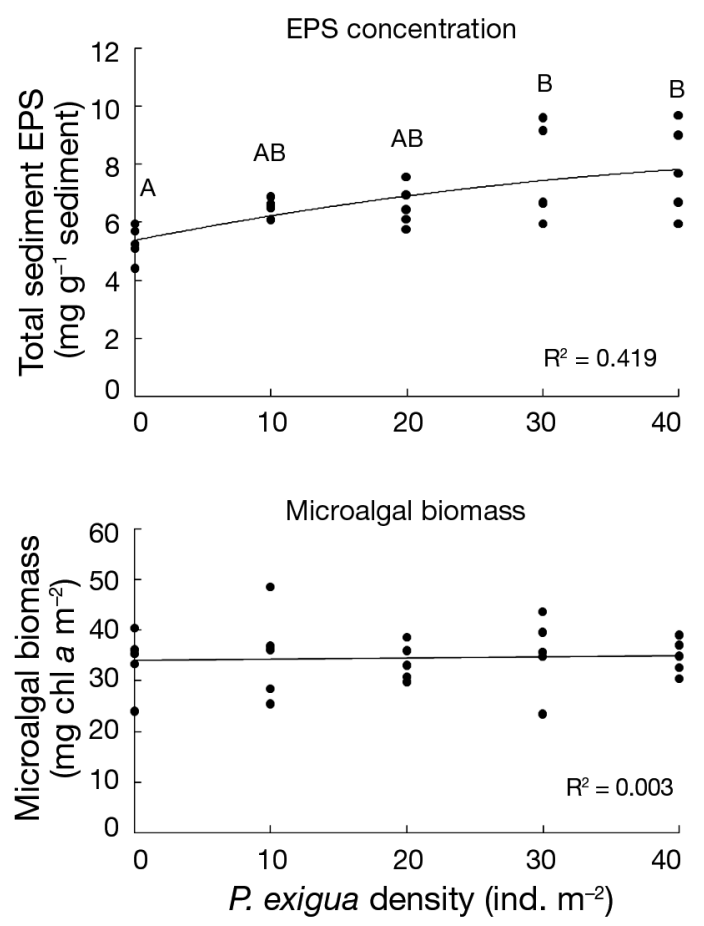

Fig. 1. Variations in sediment extracellular polymeric substance (EPS) levels and microalgal biomass with increasing densities of Parvulastra exigua. Shared letters above treatments indicate no significant difference

cantly among all 5 density treatments of Parvulastra exigua.

Taxonomic richness of microalgae (ANOVA: $F_{4,20}=$ 4.06, $\mathrm{p}=0.014$; Fig. 3) was significantly affected by starfish density. Richness was significantly greater at starfish densities of 20 and 30 ind $\mathrm{m}^{-2}$ compared to controls. Microalgal richness was unimodally related to starfish density $\left(\mathrm{R}^{2}=0.447, \mathrm{p}=0.001\right)$. Microalgal abundance was also significantly affected by starfish densities (ANOVA: $F_{4,20}=6.370, \mathrm{p}=0.0017$; Fig. 3), being significantly greater in the control than at densities of 40 ind. $\mathrm{m}^{-2}$. Abundance of microalgae was best related to starfish density by a unimodal function $\left(\mathrm{R}^{2}=0.504, \mathrm{p}<0.001\right)$. Starfish densities significantly affected microalgal diversity (Shannon-Wiener index, ANOVA: $F_{4,20}=4.50, p=0.0094 ;$ Fig. 3 ), with values in controls being significantly lower that all other starfish densities $(p<0.05)$. Shannon-Wiener diversity and starfish density displayed a unimodal relationship $\left(\mathrm{R}^{2}=0.390, \mathrm{p}=0.004\right)$.

Of the 104 microalgal taxa identified, 20 showed significant responses to Parvulastra exigua densities (Table 1). Nine taxa displayed decreasing linear relationships, 1 taxon increased linearly, 7 showed humpshaped unimodal and 3 displayed U-shaped unimodal patterns.

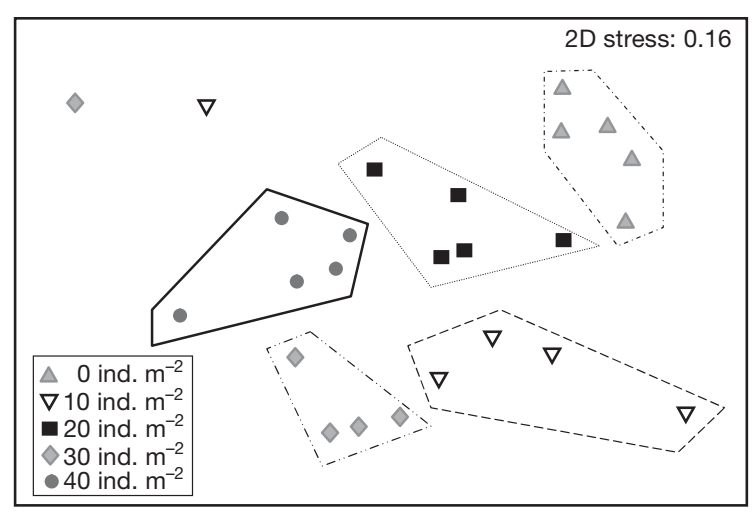

Fig. 2. Non-metric multidimensional scaling ordination showing spatial variation in microalgal community structure among the 5 Parvulastra exigua density treatments
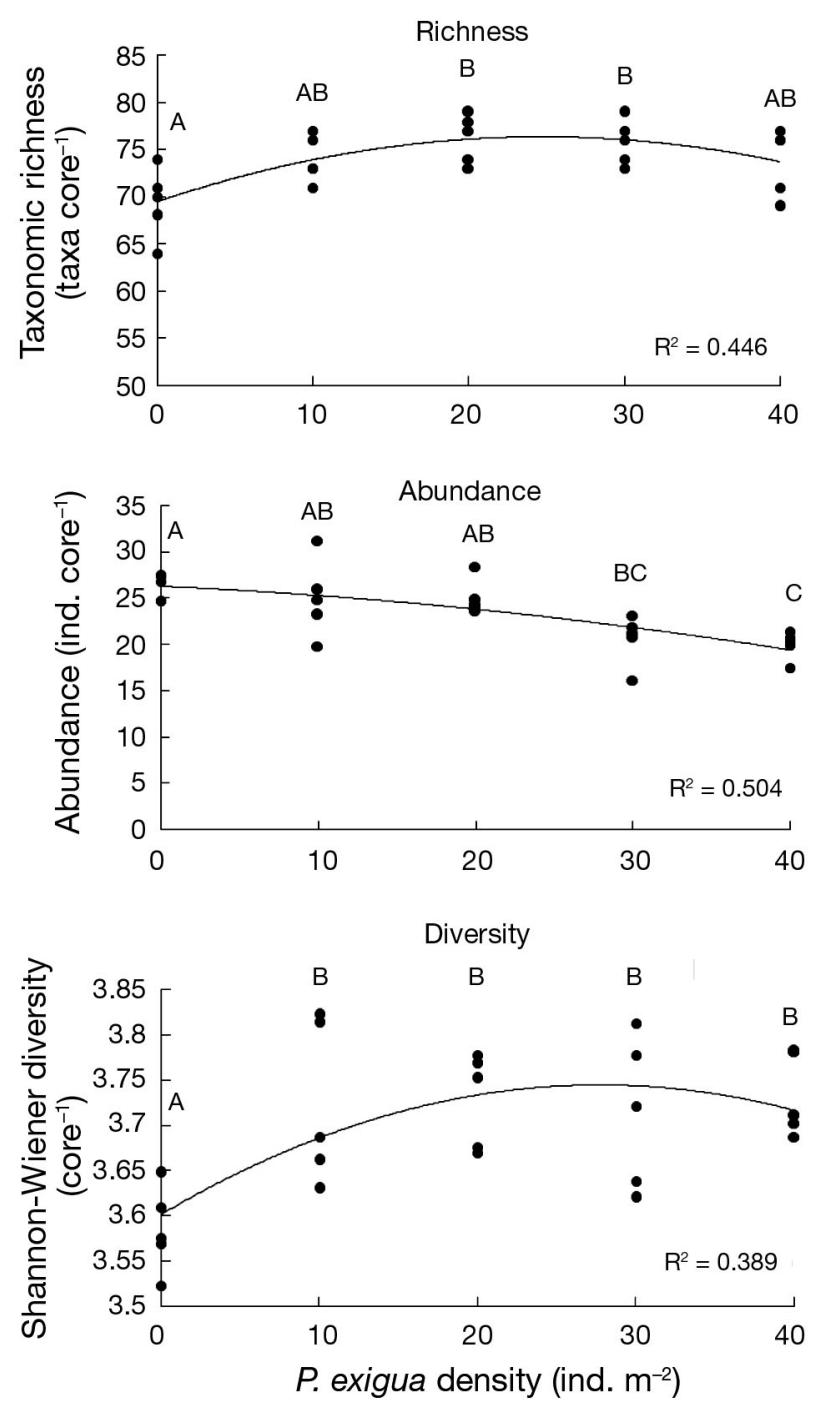

Fig. 3. Relationships between the density of Parvulastra exigua and taxonomic richness, abundance and ShannonWiener diversity 
Table 1. Summary statistics of regression analyses between abundance of different microalgal taxa and Parvulastra exigua density

\begin{tabular}{|lccrr|}
\hline Taxon & Function & Response & $\mathrm{R}^{2}$ & $\mathrm{p}$ \\
\hline Pennate sp. 1 & Linear & Decreasing & 0.647 & $<0.001$ \\
Pennate sp. 2 & Linear & Decreasing & 0.275 & 0.007 \\
Biraphideae sp. 1 & Linear & Decreasing & 0.230 & 0.015 \\
Pennate sp. 3 & Linear & Decreasing & 0.411 & 0.001 \\
Pennate sp. 4 & Linear & Decreasing & 0.536 & $<0.001$ \\
Biraphideae sp. 2 & Linear & Decreasing & 0.298 & 0.005 \\
Pennate sp. 5 & Linear & Decreasing & 0.488 & $<0.001$ \\
Biraphideae sp. 3 & Linear & Decreasing & 0.300 & 0.005 \\
Monoraphideae sp. 1 & Linear & Decreasing & 0.294 & 0.005 \\
Biraphideae sp. 4 & Linear & Increasing & 0.259 & 0.009 \\
Pennate sp. 6 & Quadratic & Hump-shaped & 0.335 & 0.011 \\
Pennate sp. 7 & Quadratic & Hump-shaped & 0.320 & 0.014 \\
Pennate sp. 8 & Quadratic & Hump-shaped & 0.361 & 0.007 \\
Biraphideae sp. 5 & Quadratic & Hump-shaped & 0.266 & 0.033 \\
Pennate sp. 9 & Quadratic & Hump-shaped & 0.372 & 0.006 \\
Biraphideae sp. 6 & Quadratic & Hump-shaped & 0.264 & 0.035 \\
Pennate sp. 10 & Quadratic & Hump-shaped & 0.533 & $<0.001$ \\
Cyanobacteria sp. 1 & Quadratic & U-shaped & 0.482 & 0.001 \\
Pennate sp. 11 & Quadratic & U-shaped & 0.732 & $<0.001$ \\
Biraphideae sp. 7 & Quadratic & U-shaped & 0.432 & 0.002 \\
& & & & \\
\hline
\end{tabular}

\section{DISCUSSION}

This experimental test of the influence of Parvulastra exigua on intertidal soft-sediment microalgal assemblages produced interesting findings that are pertinent to understanding grazer effects in marine ecosystems. The role of $P$. exigua in reducing microalgal abundance and enhancing EPS, microalgal richness and diversity (at intermediate densities) is similar to the effects of this starfish observed on soft-sediment macrofauna (Pillay et al. 2010a). In the Pillay et al. (2010a) study, $P$. exigua negatively affected macrofaunal abundance and biomass, linearly enhanced bacterial density and promoted diversity at intermediate densities. The negative effect of $P$. exigua on microalgal abundance in the present study is comparable to the findings of Jackson et al. (2009), which showed that natural densities of $P$. exigua halved microalgal content in intertidal rocky shores. It was also shown that a single starfish could graze up to $60 \%$ of the epilithic microalgae beneath its stomach in a single feeding event averaging $22 \mathrm{~min}$ (Jackson et al. 2009). Grazer-induced reductions in microalgal levels have also been reported in studies of marine softsediment gastropods and amphipods (Morrisey 1988, Pillay et al. 2009).

It is interesting to note that in the present study, we observed no effect of Parvulastra exigua on microalgal biomass (chl a levels) but a negative effect on abundance of microalgae. One possible explanation for this is that increasing grazing pressure caused a shift in size of microalgae, with individuals becoming larger. The lack of an effect on microalgal biomass is surprising, as several studies have reported grazer-induced reductions in chl a levels (Jackson et al. 2009, Pillay et al. 2009, 2010a).

The most significant finding arising from the present study was the enhancement of EPS levels on the sediment surface with increasing densities of Parvulastra exigua. This ability of $P$. exigua may be due to 2 mechanisms. Firstly, $P$. exigua feeds by everting its stomach over the substrate, leaving behind a mucus web (Branch \& Branch 1980), which may enhance EPS levels through the addition of carbohydrates and other organic compounds (Wotton 2004a,b). Secondly, the elevation of surficial bacterial density by P. exigua (Pillay et al. 2010a) can elevate levels of polymeric substances through exudation. $P$. exigua can enhance bacterial levels by 'cropping' older cells, allowing new colonizers to proliferate. The addition of bacteria to faeces of $P$. exigua may also enhance bacterial growth on sediment (Hargrave 1970). Microalgal exudates are unlikely to contribute to the elevation of EPS levels recorded in the present study, as $P$. exigua had negative effects on microalgal abundance and no effect on biomass.

The hump-shaped unimodal relationship recorded between densities of Parvulastra exigua and microalgal richness and diversity has also been recorded in experimental tests of this starfish on soft-sediment macrofauna (Pillay et al. 2010a). Unimodal effects on diversity have been recorded in studies of various other grazers in marine ecosystems (Paine \& Vadas 1969, Lubchenco 1978). Unimodal relationships between grazer density and richness and diversity are often explained using the intermediate disturbance hypothesis ( $\mathrm{IDH}_{;}$Connell 1978). The IDH can be viewed as a model in which diversity peaks under intermediate levels of disturbance (Shea et al. 2004). In the context of grazer effects, this hypothesis proposes that competitive exclusion reduces diversity at low levels of grazing pressure, where established dominants prevent colonisation by sub-dominants. Under high grazing pressure, grazers eliminate all but a few resilient species with high colonization rates. At intermediate grazing pressure, the competitive edge held by dominant species is reduced, allowing less dominant species to colonise ecosystems, thus maximising species richness by promoting co-existence of dominants and sub-dominants or rare species (Petraitis et al. 1989). Grazing at intermediate intensities can also 
create habitat patches of different successional ages, thus enabling early- and late-stage communities to coexist (Connell 1978, Huston 1979, 1994).

There are 3 fundamental requirements for the operation of the IDH: a disturbance must occur, competition must occur in the system of interest and the community must have a predictable successional sequence of species that is to be reset as a result of the disturbance (Chesson \& Huntly 1997, Shea et al. 2004). The biggest obstacle to applying the IDH to interpret the effects of grazers in aquatic soft sediments is that competition and competitive exclusion have rarely been shown to be of importance in structuring communities in these ecosystems relative to hard substrata (Wilson 1990, Seitz 1998, Little 2000). Food limitation in soft sediments has also been questioned (Seitz 1998), probably because energetic resources are not limited to the surface and are available interstitially with depth.

On the basis of these pieces of evidence, it is conceivable that the unimodal relationship between starfish density and microalgal diversity in this study may not be entirely due to competitive interactions alone. Based on the promotive effect of Parvulastra exigua on sediment EPS, we propose a model based on non-competitive interactions by which this starfish promotes richness and diversity at intermediate grazing intensities to create patterns similar to those predicted by the IDH (Fig. 4). This is relevant given that
IDH patterns can theoretically be generated by various interactive mechanisms (Shea et al. 2004).

In this model, Parvulastra exigua enhances microalgal diversity at moderate densities by enhancing sediment EPS levels, which can have a range of ecological effects that ultimately positively affect microalgal diversity. However, beyond this intermediate density, grazing pressure outweighs the promotive effects of EPS, and selects for the most rapid microalgal colonisers.

The effect of EPS in enhancing microalgal diversity at intermediate densities of Parvulastra exigua can be generated through various pathways. Firstly, elevated levels of EPS can stabilize sediments and prevent the erosion of vulnerable species from the sediment into the water column. Biofilm EPS are known to reduce sediment erodibility by binding the topmost layer, but also promote laminar flow of water over the bed, further preventing erosive loss of surface sediments and organisms (Paterson \& Hagerthey 2001). In this manner, EPS may enhance microalgal diversity by retaining species that are vulnerable to erosion by wave action.

Secondly, increased EPS levels may act as adhesive traps for microalgal cells and propagules from the water column (Wotton 2004b). There is indirect evidence for this mechanism from the work of Connor (1986), who showed that EPS in the form of mucus

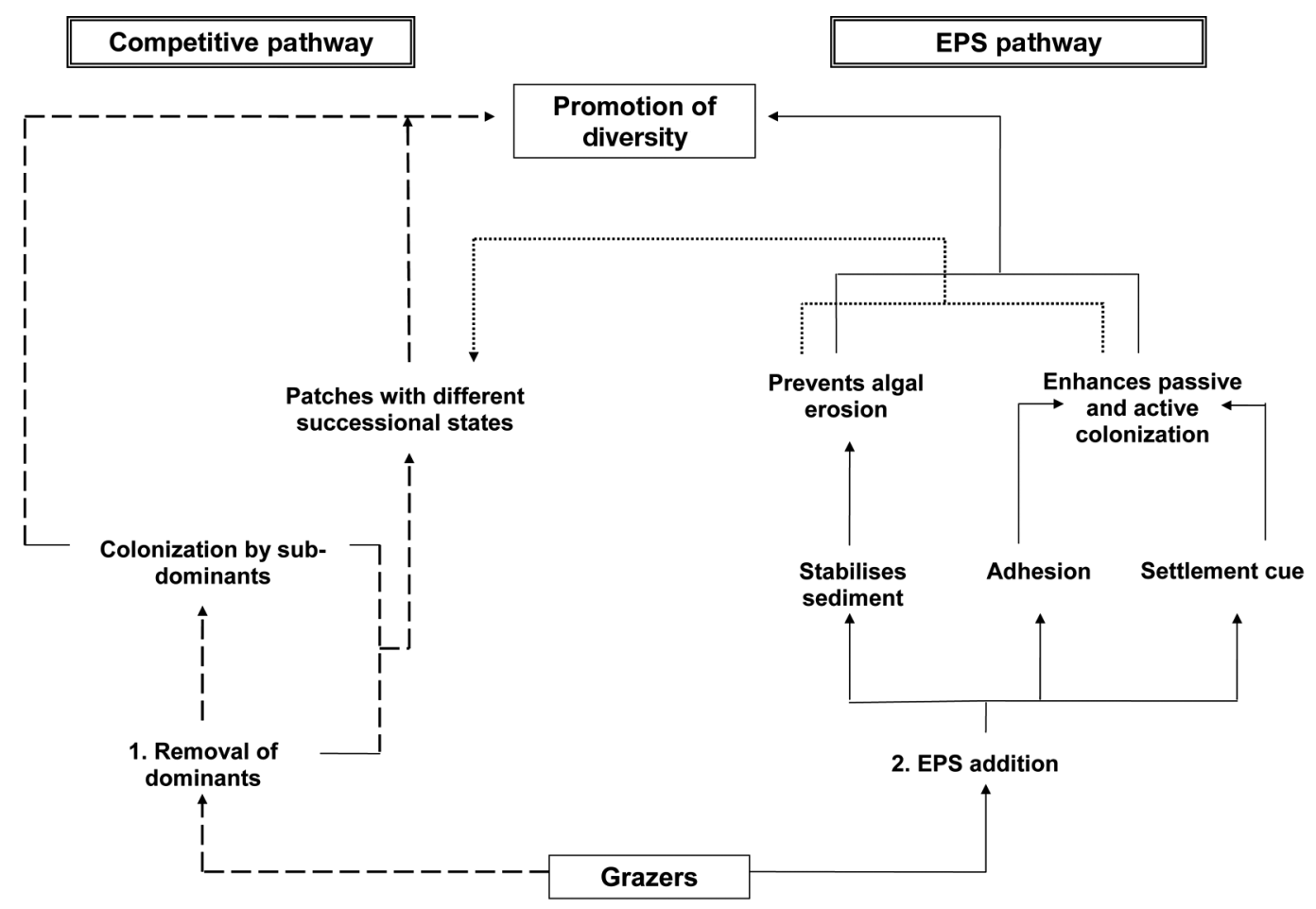

Fig. 4. Conceptual model showing the direct and interactive (dotted) effects of competitive (dashed) and extracellular polymeric substance (EPS; solid) pathways in enhancing microalgal diversity at intermediate grazing intensity 
trails of gastropod limpets trap microalgae and may also enhance microalgal growth. Importantly, the carbohydrate content of mucus was linked to the trapping ability of mucus. Santelices \& Bobadila (1996) also showed that the pedal mucus of various intertidal rocky gastropods retains seaweed propagules. The mucus lining of burrowing marine invertebrates is also suggested to trap microalgal cells from the water column (Griffen et al. 2004). These studies thus indicate that EPS enhancement by Parvulastra exigua, either through mucus secretion or microbial origin, could enhance microalgal diversity by trapping cells or propagules from the water column.

Lastly, EPS may function as a settlement cue for microalgae. Not much is known about the role of EPS as biochemical signals for microalgal settlement, but biofilm EPS have been shown to trigger the settlement of numerous invertebrate species in both rocky and sedimentary ecosystems (Wotton 2004b, Patil \& Anil 2005, Lam et al. 2005). It is known that bacterial exopolymers are requisite for the attachment of microalgae (Connor 1986 and references therein), but the precise mechanisms involved are poorly reported relative to those involved with marine invertebrate settlement. Although we advocate a promotive effect of EPS on microalgal settlement, it is also plausible for EPS to indirectly reduce microalgal recruitment by promoting settlement of invertebrate larvae and, therefore, grazing intensity.

In reality, there is no way of separating competitive and non-competitive pathways based on this experiment, and it is likely that both mechanisms interact under natural conditions to influence diversity. Both mechanisms (IDH and EPS) can also be used to explain the responses of specific microalgal taxa to increasing densities of Parvulastra exigua. Nine taxa decreased linearly in abundance, probably indicating that these taxa are most sensitive to grazing by $P$. exigua. One taxon was positively influenced by $P$. exigua, as its abundance increased linearly with increasing starfish density. This taxon could have benefited from the removal of microalgal taxa through alleviation of competition, or from the promotive effect of EPS shown in Fig. 4. Interestingly, 7 taxa showed hump-shaped and 3 showed U-shaped responses to increasing starfish density. The hump-shaped patterns could be explained by these species being initially favoured through competitive release or EPS addition up to intermediate starfish densities, but then being overwhelmed by increasing grazing pressure. U-shaped responses of microalgal taxa could be due to initial negative effects of grazing pressure up to intermediate densities of $P$. exigua followed by promotive effects of EPS. It should be noted, however, that in 2 of the 3 cases where U-shaped unimodal curves were identi- fied as best fits, linear models also offered very close fits, with the unimodal curves offering an improved fit of 15 to $22 \%$ compared with the linear model. In the third U-shaped response observed, the unimodal curve was $65 \%$ better than the next best fit, which was the linear model.

The results of this experiment and model proposed in Fig. 4 may collectively have important implications for marine ecology. Firstly, the effects of Parvulastra exigua observed here confirm that this species plays an important role in structuring assemblages and influencing diversity and richness in marine intertidal soft sediments (Pillay et al. 2010a). The present study, along with previous research, indicates that future losses of this starfish could lead to a loss of biodiversity in intertidal sandflats of Langebaan Lagoon. Our findings also add to the current view that this grazer plays an underestimated role in intertidal and shallow marine systems. Secondly, the present study shows that grazers can have important incidental promotive effects that must be considered when understanding the mechanisms underlying grazer effects. This is especially pertinent in marine sediments, where organism-sediment interactions are intimate and may potentially supersede competitively mediated effects. Lastly, given that a variety of grazers enhance EPS levels either through mucus production (Santelices \& Bobadila 1996) or stimulation of bacteria (Pillay et al. 2010a) and that EPS play major ecological roles in marine ecosystems (Wotton 2004a), the influence of grazers on EPS may be an underestimated pathway through which grazers influence co-occurring assemblages.

Acknowledgements. Financial support for this project was provided by the Carnegie and Andrew Mellon Foundations, The University of Cape Town and The National Research Foundation. We are grateful to J. Fourie, K. Straarup, C. Watson, G. Selkirk and M. Mushabe for their assistance in the field.

\section{LITERATURE CITED}

Aller JY, Woodin SA, Aller RC (2001) Organism-sediment interactions. University of South Carolina Press, Columbia, SC

Anderson MJ (1999) Distinguishing direct from indirect effects of grazers in estuarine intertidal assemblages. J Exp Mar Biol Ecol 234:199-218

Anderson MJ, Underwood AJ (1997) Effects of gastropod grazers on recruitment and succession of an estuarine assemblage: a multivariate and univariate approach. Oecologia 109:442-453

Arrontes J, Underwood AJ (1991) Experimental studies on some aspects of the feeding ecology of the intertidal starfish Patiriella exigua. J Exp Mar Biol Ecol 148:255-269

Branch GM, Branch ML (1980) Competition between Callana 
tramoserica (Sowerby) (Gastropoda) and Patiriella exigua (Lamarck) (Asteroidea), and their influence on algal standing stocks. J Exp Mar Biol Ecol 330:245-260

Chesson P, Huntly N (1997) The roles of harsh and fluctuating conditions in the dynamics of ecological communities. Am Nat 150:519-553

Connell JH (1978) Diversity in tropical rainforests and coral reefs. Science 199:1302-1310

Connor VM (1986) The use of mucous trails by intertidal limpets to enhance food resources. Biol Bull 171:548-564

Day JH (1959) The biology of Langebaan Lagoon: a study of the effect of shelter from wave action. Trans R Soc S Afr 35:475-547

Decho AW (1990) Microbial exopolymer secretions in ocean environments: their role(s) in food webs and marine processes. Oceanogr Mar Biol Annu Rev 28:73-153

Dubois M, Gilles KA, Hamilton JK, Reber PA, Smith F (1956) Colorimetric method for determination of sugars and related substances. Anal Chem 28:350-356

Flint RW, Goldman CR (1975) The effects of a benthic grazer on the primary productivity of the littoral zone of Lake Tahoe. Limnol Oceanogr 20:935-944

> Griffen BD, DeWitt TH, Langdon C (2004) Particle removal rates by the mud shrimp Upogebia pugettensis, its burrow, and a commensal clam: effects on estuarine phytoplankton abundance. Mar Ecol Prog Ser 269:223-236

Hargrave BT (1970) The effect of a deposit-feeding amphipod on the metabolism of benthic microflora. Limnol Oceanogr 15:21-30

- Huston MA (1979) A general hypothesis of species diversity. Am Nat 113:81-101

Huston MA (1994) Biological diversity: the coexistence of species on changing landscapes. Cambridge University Press, New York, NY

> Jackson AC, Murphy RJ, Underwood AJ (2009) Patiriella exigua: grazing by a starfish in an overgrazed intertidal system. Mar Ecol Prog Ser 376:153-163

> Lam C, Harder T, Qian PY (2005) Induction of larval settlement in the polychaete Hydroides elegans by extracellular polymers of benthic diatoms. Mar Ecol Prog Ser 286: $145-154$

Levinton JS, Stewart S (1982) Marine succession: the effect of two deposit-feeding gastropod species on the population growth of Paranais litoralis Muller 1784 (Oligochaeta). J Exp Mar Biol Ecol 59:231-241

Little C (2000) The biology of soft shores and estuaries. Oxford University Press, New York, NY

Little C, Kitching JA (1996) The biology of rocky shores. Oxford University Press, New York, NY

Lubchenco J (1978) Plant species diversity in a marine intertidal community: importance of herbivore food preferences and algal competitive ability. Am Nat 112:23-39

Lubchenco J, Gaines SD (1981) A unified approach to marine plant-herbivore interactions. I. Populations and communities. Annu Rev Ecol Syst 12:405-437

McClintock JB, Lawrence JM (1985) Characteristics of foraging in the soft-bottom benthic starfish Luidia clathrata (Echinodermata: Asteroidea): prey selectivity, switching behavior, functional responses and movement patterns. Oecologia 66:291-298

Morrisey DJ (1988) Differences in effects of grazing by deposit-feeders Hydrobia ulvae (Pennant) (Gastropoda: Prosobranchia) and Corophium arenarium (Crawford) (Amphipoda) on sediment microalgal populations. II. Quantitative effects. J Exp Mar Biol Ecol 118:43-53

Paine RT (1974) Intertidal community structure: experimental studies on the relationship between a dominant competi- tor and its principal predator. Oecologia 15:93-120

Paine RT, Vadas RL (1969) The effects of grazing by sea urchins, Strongylocentrotus spp., on benthic algal populations. Limnol Oceanogr 14:710-719

Paterson DM, Hagerthey SE (2001) Microphytobethos in contrasting coastal ecosystems: biology and dynamics. In: Reise K (ed) Ecological comparisons of sedimentary shores. Ecological studies, Vol 151, Springer-Verlag, Berlin, p 276-293

Patil JS, Anil AC (2005) Influence of diatom exopolymers and biofilms on metamorphosis in the barnacle Balanus amphitrite. Mar Ecol Prog Ser 301:231-245

Peterson CH (1979) Predation, competitive exclusion, and diversity in the soft sediment benthic communities of estuaries and lagoons. In: Livingston RJ (ed) Ecological processes in coastal and marine systems. Plenum Press, New York, NY, p 233-264

Petraitis PS, Latham RE, Niesenbaum RA (1989) The maintenance of species-diversity by disturbance. Q Rev Biol 64: 393-418

Pillay D, Branch GM, Forbes AT (2007) Effects of Callianassa kraussi on microbial biofilms and recruitment of macrofauna: a novel hypothesis for adult-juvenile interactions. Mar Ecol Prog Ser 347:1-14

> Pillay D, Branch GM, Steyn A (2009) Complex effects of the gastropod Assiminea globulus on benthic community structure in a marine-dominated lagoon. J Exp Mar Biol Ecol 380:47-52

> Pillay D, Branch GM, Steyn A (2010a) Unexpected effects of starfish grazing on sandflat communities following an outbreak. Mar Ecol Prog Ser 398:173-182

Pillay D, Branch GM, Griffiths CL, Williams C, Prinsloo A (2010b) Ecosystem change in a South African marine reserve (1960-2009): role of seagrass loss and anthropogenic disturbance. Mar Ecol Prog Ser 415:35-48

Santelices B, Bobadila M (1996) Gastropod pedal mucus retains seaweed propagules. J Exp Mar Biol Ecol 197: 251-261

Seitz RD (1998) Incorporation of soft-sediment systems into a model of marine benthic community regulation. Mar Freshw Res 49:817-826

Shea K, Roxburgh SH, Rauschert ESJ (2004) Moving from pattern to process: coexistence mechanisms under intermediate disturbance regimes. Ecol Lett 7:491-508

> Stevenson JP (1992) A possible modification of the distribution of the intertidal seastar Patiriella exigua (Lamarck) (Echinodermata, Asteroidea) by Patiriella calcar (Lamarck). J Exp Mar Biol Ecol 155:41-54

Taylor JC, Harding WR, Archibald CGM (2007) A methods manual for the collection, preparation and analysis of diatom samples. Version 1.0. Water Research Commission Report TT 281/07, Gezina

Underwood GJC, Paterson DM (1995) The measurement of microbial carbohydrate exopolymers from intertidal sediments. Limnol Oceanogr 40:1243-1253

van Loosdrecht MCM, Liklem J, Norde W, Zehnder AJB (1990) Influences of interfaces on microbial activity. Microbiol Rev 54:75-87

Virnstein RW (1978) Predator caging experiments: caution advised. In: Wiley ML (ed) Estuarine interactions. Academic Press, London, p 261-273

- Wilson WH (1990) Competition and predation in marine softsediment communities. Annu Rev Ecol Syst 21:221-241

> Wotton RS (2004a) The ubiquity and many roles of exoploymers (EPS) in aquatic systems. Sci Mar 68:13-21

> Wotton RS (2004b) The essential role of exoplymers (EPS) in aquatic systems. Oceanogr Mar Biol Annu Rev 42:57-94 